\title{
Application of Blending Learning Based on Network Learning Space in Teaching Design of Digital Art
}

\author{
https://doi.org/10.3991/ijet.v14i03.10107 \\ Jian Wang \\ University of Science and Technology Liaoning, Anshan, China \\ 13332110005 esina.cn
}

\begin{abstract}
In traditional face-to-face teaching mode, the teacher plays the leading role in the learning process, while students are in the subordinate status. Such learning mode can be easily interrupted due to the ending of classroom teaching time. To let students keep continuous learning, network learning mode based on information technology emerges. In network learning mode, students have strong learning autonomy, and can arrange learning contents and progress according to their ability and time. However, network learning mode requires students owning strong self-discipline ability to plan and arrange the learning contents and practice. A blending learning mode which can deeply integrate online learning and face-to-face teaching was established on the basis of network learning space, and applied in teaching practice of Digital Art. The results of teaching practice showed that, blending learning has significant effect on improving teaching effect of Digital Art.
\end{abstract}

Keywords_-Digital Art; network learning space; blending learning; teaching design

\section{Introduction}

In traditional education system, students mainly learn according to teacher's guidance. In such mode, the teacher plays the leading role, while students are in the subordinate status. Such learning mode can be easily interrupted due to the ending of classroom teaching time [1]. To let students keep continuous learning, network learning mode based on information technology emerges. In network learning mode, students have strong learning autonomy, and can arrange learning contents and progress according to their ability and time [2]. However, network learning mode requires students owning strong self-discipline ability to plan and arrange the learning contents and practice. If students lack sufficient self-discipline ability, the learning process will become formalistic. In such case, a new learning mode which can combine advantages of two learning modes and abandon their shortcomings is needed to help teachers improve teachers' teaching efficiency and students' learning efficiency. In this study, a blending learning mode based on network learning space was constructed and applied in teaching practice of Digital Art. The mode can deeply integrate advantages of online learning and face-to-face teaching. 


\section{State of the Art}

As information technology continues to develop and smart devices are popularized continuously, online learning has become an important learning mode. Online learning mode can help teachers and students break through time and space limit, and freely arrange learning plans according to their learning needs and time arrangement [3]. However, as online education concept continues to develop, the defects of such learning mode are perceived by more and more scholars. On the one hand, online learning has high requirements for learners' self-discipline. On the other hand, online learning and face-to-face classroom education fail to be really integrated [4]. In such case, blending learning mode arouses more and more attention and researches by education workers. Rovai [5] considered, blending learning is the mixture of classroom and online learning, and it includes convenience of some online courses, and avoids face-to-face contact between students and teachers. The research result shows that blending learning course can make students generate stronger community consciousness than traditional or completely online course. Cukurova et al. [6] identified crucial aspects of the collaborative problem solving process in practicebased learning activities with an analysis framework. They developed a mixedmethods approach to generate a theoretically robust and generalizable analysis framework. In addition, the framework is based on data and hence applicable to reallife learning contexts. The experiment verified the method could effectively improve teaching effect. Cost et al. [7] applied blending teaching in Software Project Management course at the "Politehnica" University of Bucharest and found through comparison it with traditional teaching that, students preferred to blending teaching.

In domestic researches, many scholars studied the application of blending learning in teaching design from the perspective of practice. Duo et al. [8] studied teaching design based on blending learning from the perspective of problem solving, took learning-based on problem solving as the design line and integrated it in learning learning process to construct the diversified blending learning activities. Yang [9] investigated the blending teaching under MOOC environment, and made up for the defects of traditional teaching mode by integrating MOOC online education mode in the teaching design based on blending learning. Based on exiting researches, the blending teaching mode based on network learning space was proposed in this study, and applied in teaching design of Digital Art. The innovation points of this study are mainly reflected in two aspects.

- The blending teaching mode based on network learning space was proposed, and the complete teaching activities were design to provide solid support for improving teaching effect of Digital Art.

- A low-threshold method to product MOOC video was designed to greatly reduce complexity and difficulty of MOOC video production so that teachers could provide richer learning resources for blending learning. 


\section{Theory Construction}

\subsection{Blending learning mode}

The blending learning mode is relative to traditional face-to-face teaching mode and online learning mode based on information technology [10]. In face-to-face learning mode, students' attention concentrates relatively, and the learning efficiency can be guaranteed, but the time and space arrangement is fixed. Online learning mode breaks through time and space limit, and can allow students to learn anytime and anywhere. However, since students' self-discipline degree differs, it is hard to ensure learning effect. Blending learning mode combines advantages of the two learning modes to fully improve learning efficiency. In blending learning mode, the teachers can play monitoring and guiding role in teaching, and students' learning initiative and creativity can improve. Through organic combination of online and offline learning modes, blending learning mode can help students achieve uninterrupted and contiguous learning, and can significantly improve learning effect.

The key to blending teaching mode lies in organic combination of online learning and offline learning. Online learning and offline learning play different roles in the whole learning process, and include different activities. The activities included in blending learning mode are shown in Fig.1.

In offline learning, 5 activities are mainly included:

- Review previous learning content;

- Explain new knowledge points and arrange online learning tasks;

- Students ask questions, and teachers answer and summarize;

- Class exercise;

- Group discussion

Online learning continues and supplements offline learning and includes 4 activities:

- View MOOC video for independent study;

- Collect learning data;

- Complete online test;

- Analyze and summarize problems.

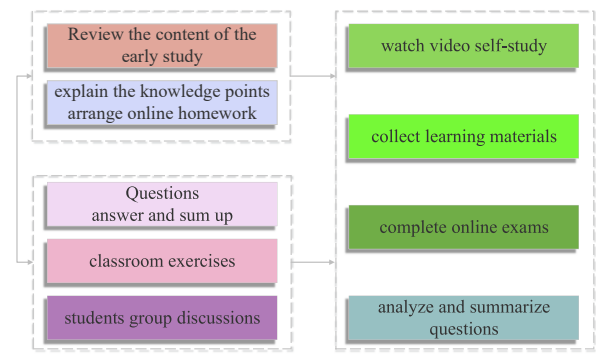

Fig. 1. Learning activity diagram of blending learning mode 
Because of changes in learning modes and learning activities, traditional course assessment system which consists of classroom performance, mid-term examination and final examination needs corresponding concepts to adapt to requirements of blending learning mode. In other words, course assessment system should bring online learning mode in it. In blending learning mode, course assessment system will adopt the value orientation of equal attention to goal and process so as to achieve more comprehensive and fair evaluation. Based on this value orientation, teaching assessment system of blending learning mode can be divided into four modules: course learning assessment, MOOC platform learning assessment, final comprehensive assessment, and MOOC platform test, as shown in Fig.2. The weights of various modules and their sub-modules in the total score can be adjusted by teachers according to course teaching objective. If the course mainly involves practice, the larger weight proportion can be given in the modules which embody process assessment such as MOOC platform learning and classroom learning.

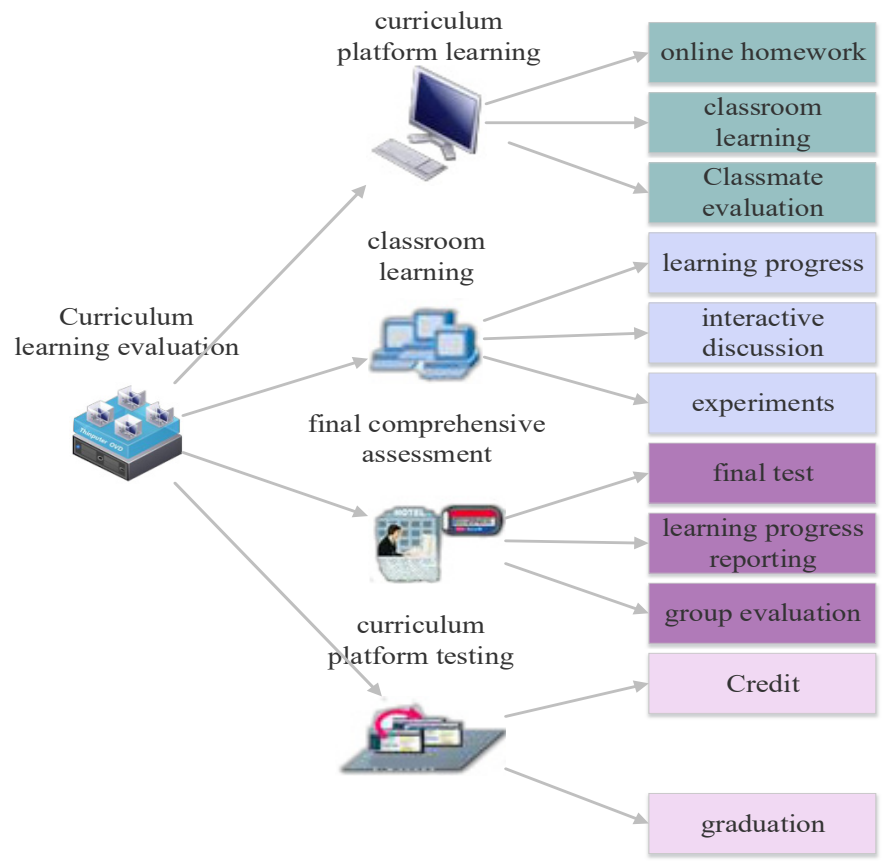

Fig. 2. Course assessment system of blending learning mode

\subsection{Student-oriented teaching design based on network learning space}

Network learning space and problem solving learning: Problem solving learning [1] is an appropriate learning and teaching method to achieve constructivism learning idea. In school education, problem solving has become an important method, and it is used to promote development of students' cognitive strategy, thinking method and creativity. In the process of problem solving, external representations are 
often needed to solve problems and help students structuralize problems. For example, computer tool, concept map, diagram, form and other media tools can be used to describe the state of problems, hide the irrelevant part and organize the important part according to problem situations. Relevant researches show that, the application of diversified external representations is closely related to successful problem solving.

Network learning space is constructed as the infrastructure of creative learning mode. In problem solving process, informatization auxiliary tools such as structural modeling device and graphical representation are used to help learners solve problems [12]. For example, structural representation of problem solving is established by proof tree in geometry demonstration to help learners establish relationship between known conditions and unknown conditions. In addition, animation, video and other multimedia techniques can be used to create visual objects and show invisible or abstract concepts in nature. Thus, when learners construct external representation of problems, network learning space can provide them with multiple effective informatization auxiliary tools.

Function module design of network learning space: Network learning space gathers digital education resources and intellectual resources by continuously development, intersection and integration of information technology, provides learners with virtual-real fused learning resource environment, achieves intelligent and individualized learning, and constructs educational cloud service system of virtual-real integrated education ecology in the information-based society. All teachers and students can design their own individualized learning space in the space and meet their diversified needs. As shown in Fig.3, network learning space is designed and constructed through three basic attributes: learning, society and environment. From the perspective of user role, network learning space is divided into student space, teacher space and administrator space. The spaces of different roles are connected through materialized and dynamic learning resources to meet space construction requirement among each element, i.e. data interconnection, information communication, resource interconnection and service interconnection.

Student space is a virtual place for learners' independent study, collaborative exploration, introspection and communication. Its core features include networked storage and sharing of digital education resources. It provides learners with intelligent and adaptive services, and supports learners to acquire individualized learning resource and freely participate in learning activities.

Student space mainly includes the following modules.

- Learning resource presentation and representation module provides learners with rich diversified learning resources and thorough navigation strategy to reduce the difficulty in acquiring and managing knowledge.

- Interaction and cooperation module provides support for immediate interaction among students and between teachers and students, structural representation of problems, solutions and works evaluation, and gives full play to cooperation and encourage roles of peers and guiding role of teachers. 
- Learning and operation behavior recording module, and evaluation and introspection module provide real-time data to promote learners' self-supervision and introspection.

- Individualized learning module guides learners to continuously plan and adjust learning process and progress under the support of behavior data, to solve problems and complete learning tasks under the support of visualized representation tools and to promote learners' sense of space presence.

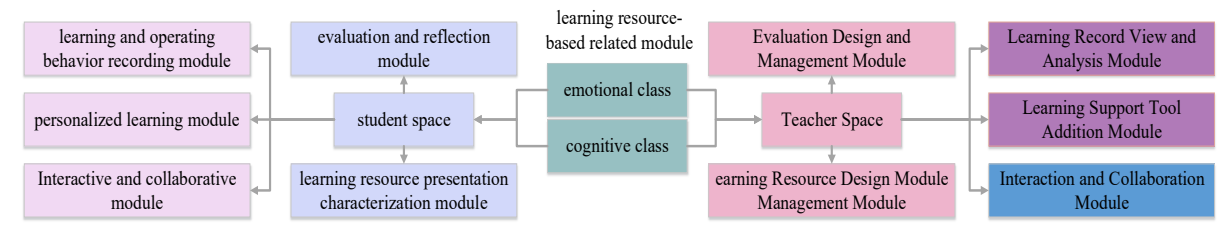

Fig. 3. Student-oriented teaching design based on network learning space

Teacher space is a virtual place for teacher's network role play, and mainly includes the following modules.

- Learning resource design and management module adopts the visual editor so that teachers can easily design visualized learning navigation and teaching materials which can be presented and represented by multiple ways.

- Interaction and cooperation module is used by teachers to participate in cooperation, exchange and exploration among students in the capacity of learner partner.

- Learning support tool adding module brings convenience for teachers to design appropriate support to promote learners' individualized learning.

- Learning record viewing and analyzing module is synchronous with learners' learning and operation behavior record data in student space, and provides data support for teachers to design teaching support and evaluate teaching.

Association module as the backstage server of space associates cognitive interaction and affective interaction of teachers and students dominated by learning resource, learning support and learning feedback and forms dynamic interaction behavior chain under technical support: behavior data collection - cognition process analysis - individualized learning support. Besides, it can help solve problems of learners in the learning process, reduce undergraduates' learning anxiety, improve network learning efficiency and better adapt to network learning space and learning mode. 


\section{Technical Support}

\subsection{MOOC video production technology}

During construction of blending learning frame based on network learning space, MOOC based on information technology is the key point and core. MOOC is produced by information technology and published in network learning space for students. Such course form can effectively break through time and space limit to help students learn continuously. Although MOOC production technology has developed for many years, there are still some problems which give rise to difficulties for production. A low-threshold MOOC video production method was constructed in this study. The advantage of this method is that the teachers may not own professional audio/video processing ability, and they can produce MOOC videos with high quality only by proficiently applying Office software such as PPT, Word and iMovie. Such method decomposes complex MOOC video production process into multiple simple tasks. Teachers can easily complete MOOC production through completing single tasks. Such MOOC production process includes 5 steps, as shown in Fig.4.

MOOC courseware production: Course content display of MOOC video is cored by PPT. both content frame and key points are displayed by depending on PPT. the purpose of this step is to make PPT file required by the course. But, it is necessary to note that not all course contents are put in the page, but course frame and key points should be displayed. The file is named slides.pptx.

Script production of course explanation content: Although PPT has covered main course content, it is brief in form so that teachers may be interrupted and blocked in the recording process. To let teachers explain course content smoothly and continuously, teachers should prepare the text corresponding to PPT according to their proficiency in the course content. This script file is called scripts.docx. The content of this file may be brief or detailed, as long as the fluent and continuous explanation purpose can be reached. Meanwhile, teachers need to mark the switching point of PPT page and animation in the script so as to leave the time interval for PPT file operation.

Course video recording: The task of this step is to record audio/video data according to script file (scripts.docx). Teachers utilize iMovie recording software to record pictures and voices. Finally, a video file speaking.mp4 is gained.

PPT file loading: The task of this step is to make PPT file correspond to timer shaft of course video file, switch PPT page and load PPT animation at the correct point of time. The software used is camtasia recording software. To be specific, teachers carefully listen to the voice in speaking.mp4 video file and make it correspond to text in scripts.docx file. PPT is switched at the switching point of PPT page and animation. The PPT video file gained is slideshow.mp4. Through this step, the time shaft of teaching video, audio and PPT pictures are synchronous.

MOOC video generation: The task of this step is to insert teaching video pictures in the recorded slideshow.mp4 video file. Specifically speaking, teachers insert teaching video pictures with PIP function of camtasia software in the blank of PPT page. Finally, MOOC video file can be gained through rendering. 


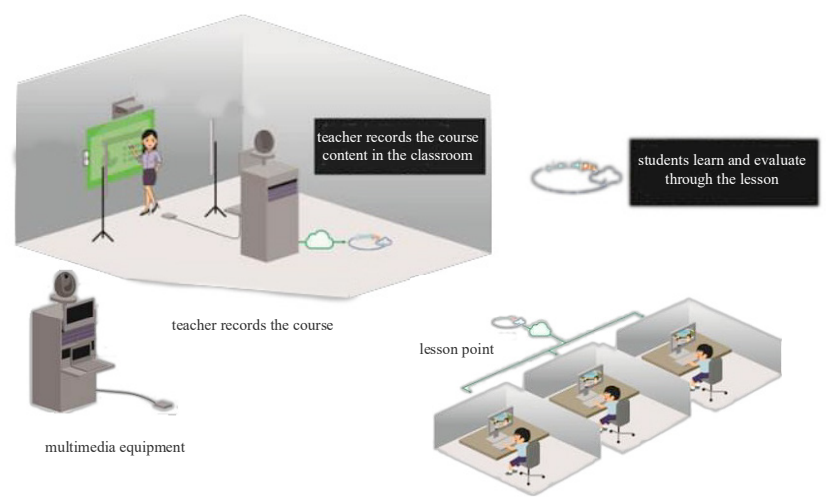

Fig. 4. MOOC video production process chart

\section{$5 \quad$ Teaching Example and Teaching Effect}

\section{$5.1 \quad$ Teaching example}

In this study, problem solving learning was used as the main line to design blending learning activities supported by network learning space from three aspects: pre-class learning promotion, classroom study and after-class consolidation and evaluation, as shown in Fig.5.

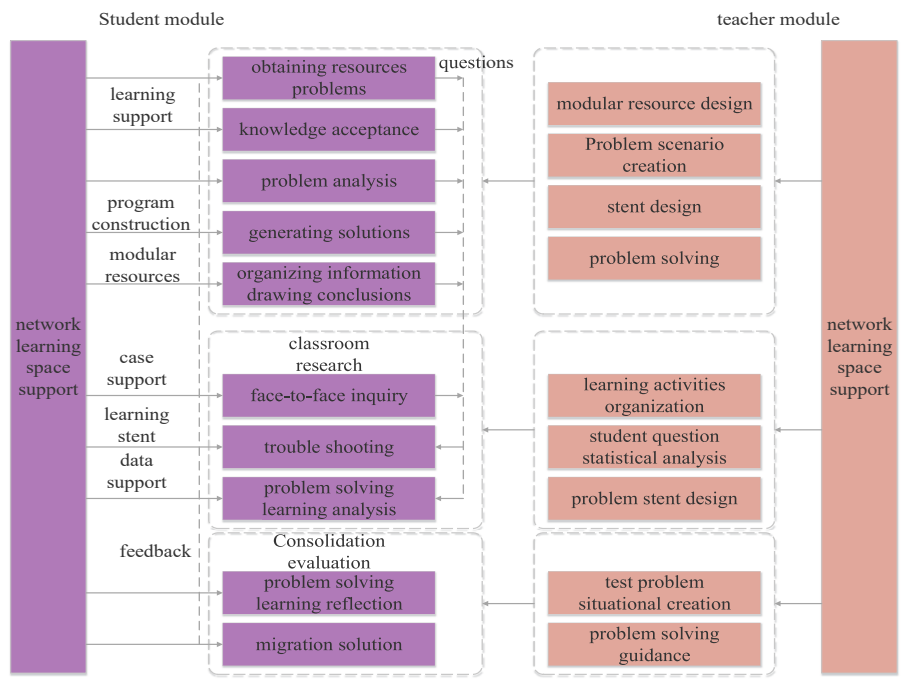

Fig. 5. Blending learning activity design based on network learning space

Pre-class learning promotion stage: To effectively motivate students' learning interest and motivation and guarantee learners' online learning efficiency, 
modularized learning content acquisition, statement-represented question viewing, problem analysis, structural representation of problems, solution generation and conclusion drawing links were designed in pre-class learning promotion stage. For the doubts in each link, students can seek help from teachers and peers through interaction and exchange tool supported by network teaching platform.

Classroom study: Doubts may appear in each link of problem solving process due to high problem complexity and insufficient concept learning. Classroom learning activities mainly include doubt solving in problem solving process, and process analysis of problem solving learning, etc. Under the learning data support of network learning space, teachers make statistics of, classify and analyze problems, and design corresponding learning support, collaborative and inquiry-based classroom learning activities. Process analysis of problem solving learning aims to guide students to rethink the key links of problem solving, and make students have a deeper understanding of problem solving process, actively expand and apply relevant knowledge. At the same time, the data of classroom learning activities also should be synchronized to behavior data analysis module of network learning space through corresponding technical support, and dynamically support follow-up online problem solving process.

After-class consolidation and evaluation: Blending learning evaluation under the perspective of problem solving learning does not simply evaluate students' knowledge memory and understanding. More importantly, it aims to test learners' problem solving transfer skills. Thus, the problems with the similar structure are provided for learners through creating the new problem situations, and problem complexity increases properly. Besides, some technical support of network learning space and learning support are removed or serve as alternative support.

In this study, learning process of Digital Art has high requirements for continuity. However, students' learning process is often interrupted due to the ending of classroom teaching time in traditional learning mode. When the next lesson begins, it is hard to ensure learning effect due to forgetting and other factors. In such case, network learning space is needed to provide continuous learning environment support for students. But, pure network learning has high requirements for students' selfdiscipline. Thus, it is not suitable for serving as a single learning mode. Therefore, blending learning mode which combines advantages of offline and online learning modes becomes an inevitable choice. In this study, the complete blending learning activity set was designed for Digital Art on the basis of network learning space to minimize the impacts of learning environment change and guarantee the high learning efficiency before class, in class and after class. To be specific, blending learning based on network learning space can be divided into three stages: pre-class learning promotion, classroom study and after-class consolidation and evaluation, as shown in Fig.5.

The main purpose of pre-class learning promotion stage is to motivate students' learning interest so that they can throw themselves in classroom study activities with great enthusiasm. Pre-class learning promotion stage mainly depends on network learning space, so learning activities also contain two major modules: students and 
teachers. The support design for pre-class learning promotion should reflect this feature, as shown in Table 1.

Table 1. Learning support of pre-class learning promotion stage

\begin{tabular}{|l|l|}
\hline \multicolumn{1}{|c|}{ Support items } & \multicolumn{1}{c|}{ Content } \\
\hline Concept name & - \\
\hline Definition & What is it? \\
\hline Purpose & What is the role? \\
\hline Application method & How to use? \\
\hline Application example & - \\
\hline
\end{tabular}

Pre-class learning promotion stage in blending learning differs from traditional face-to-face classroom education. The activities in classroom study are also influenced by network learning space. In this stage, teachers will conclude and summarize the problems that students encounter in learning process by depending on rich and detailed data support provided by network learning space, and set up targeted teaching activities to help students solve the problems. In problem solving process, teachers should guide students represent and solve problems step by step. Fig.6 shows a design case about problem solving teaching in Digital Art. The design of classroom study stage of Digital Art is shown in Table 2.

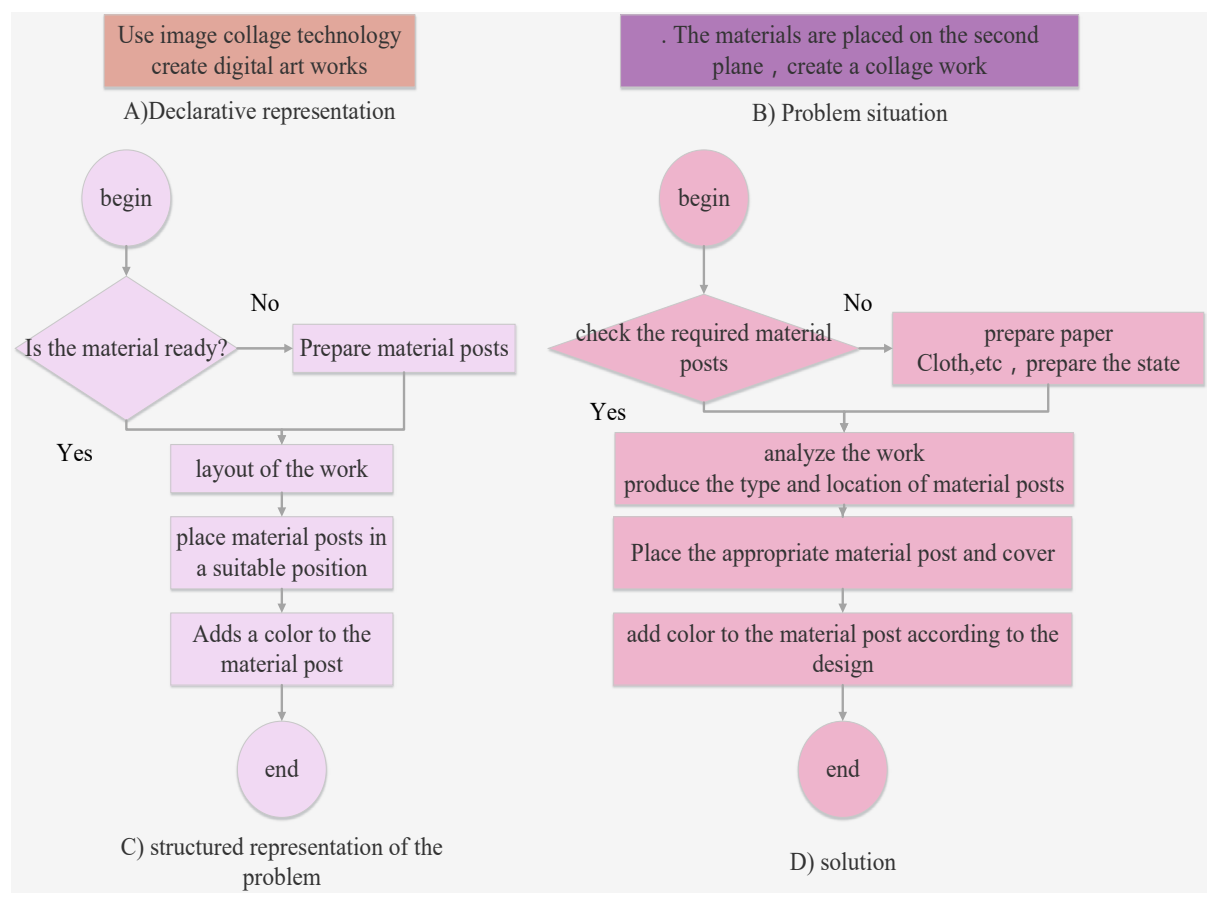

Fig. 6. Deign case of problem solving teaching in Digital Art 
Table 2. Class study teaching design of Digital Art

\begin{tabular}{|c|c|c|c|}
\hline $\begin{array}{c}\text { Teaching } \\
\text { environment }\end{array}$ & Subject & Teaching activity & $\begin{array}{l}\text { Teaching content } \\
\text { implementation }\end{array}$ \\
\hline \multirow{3}{*}{$\begin{array}{l}\text { Offline classroom } \\
\text { learning }\end{array}$} & \multirow{3}{*}{ Teachers } & Produce MOOC video & $\begin{array}{l}\text { Digital Art MOOC based } \\
\text { on network learning space }\end{array}$ \\
\hline & & Assign MOOC unit test & $\begin{array}{l}\text { Digital Art unit test based } \\
\text { on network learning space }\end{array}$ \\
\hline & & $\begin{array}{l}\text { Assign practice work of } \\
\text { Digital Art }\end{array}$ & $\begin{array}{l}\text { Color use and digital } \\
\text { picture production }\end{array}$ \\
\hline \multirow{2}{*}{$\begin{array}{l}\text { Network learning } \\
\text { space }\end{array}$} & Students & $\begin{array}{l}\text { Log in the system to view } \\
\text { MOOC video }\end{array}$ & $\begin{array}{l}\text { Preliminarily learn, } \\
\text { download courseware, } \\
\text { view video and take notes }\end{array}$ \\
\hline & Teachers & $\begin{array}{l}\text { Track students' MOOC } \\
\text { learning progress }\end{array}$ & $\begin{array}{l}\text { Record students' learning } \\
\text { duration and test scores }\end{array}$ \\
\hline \multirow{4}{*}{$\begin{array}{l}\text { Offline classroom } \\
\text { learning }\end{array}$} & \multirow{3}{*}{ Teachers } & $\begin{array}{l}\text { Collect students' questions } \\
\text { and give corresponding } \\
\text { explanations }\end{array}$ & $\begin{array}{l}\text { Decide according to } \\
\text { students' feedbacks }\end{array}$ \\
\hline & & $\begin{array}{l}\text { Organize students for } \\
\text { collaborative learning } \\
\text { through group discussion }\end{array}$ & $\begin{array}{l}\text { Intra-group mutual } \\
\text { examination of } \\
\text { assignment, mutual } \\
\text { scoring }\end{array}$ \\
\hline & & $\begin{array}{l}\text { Arrange classroom test and } \\
\text { check the learning effect to } \\
\text { further discover problems }\end{array}$ & $\begin{array}{l}\text { Depend on course teaching } \\
\text { progress }\end{array}$ \\
\hline & Students & $\begin{array}{l}\text { Intra-group discussion, } \\
\text { learning summarization }\end{array}$ & $\begin{array}{l}\text { Summarize the contents } \\
\text { learned }\end{array}$ \\
\hline
\end{tabular}

In after-class consolidation and evaluation stage, students' learning under blending learning mode will be evaluated comprehensively. Such assessment not just involves knowledge memory and understanding. More importantly, the assessment should involve knowledge transfer ability.

\subsection{Teaching effect}

To test the effect of blending learning based on network learning space in Digital Art, the research time of this study is March-July 2018. The objects chosen came from School of Architecture and Art Design, University of Science and Technology Liaoning. Two classes in same grade were chosen at random. This study was compared with traditional learning mode. In teaching practice process, the new teaching design was carried out as per features and teaching requirements of Digital Art, and students were fully guided to utilize the resources in network learning space for uninterrupted blending learning which combines online and offline learning. Meanwhile, the traditional learning mode was still applied for control group in Digital Art. Both classes adopted the same course textbooks and learning period, and went through teaching practice in the whole semester. After the teaching practice was completed, the author prepared same final examination paper for both classes to test learning effect. The test results are shown as table 3.

Judging from test score distribution, the average score of control group was obviously higher than that of control group, and the difference value was 8.8. Excellence rate of control group was also obviously higher than that of control group. Besides, the number of students with low scores in control group was significantly 
smaller than that of control group, and the failure rate of control group was also significantly lower than that of control group. The results show that blending learning mode based on network learning space can significantly improve teaching of Digital Art. The learning mode can not merely improve learning effect of excellent students, but also has certain effect on the students with poor performance.

Table 3. Comparison of scores in control group and control group

\begin{tabular}{|l|c|c|c|c|c|}
\hline \multicolumn{1}{|c|}{ Group } & $\begin{array}{c}\text { Average } \\
\text { score }\end{array}$ & $\begin{array}{c}\text { Highest } \\
\text { score }\end{array}$ & $\begin{array}{c}\text { Lowest } \\
\text { score }\end{array}$ & $\begin{array}{c}\text { Excellence } \\
\text { rate }\end{array}$ & Failure rate \\
\hline Experimental group & 86.1 & 93 & 57 & $7(15.6 \%)$ & $2(4.4 \%)$ \\
\hline Control group & 77.3 & 91 & 38 & $2(4.4 \%)$ & $8(17.8 \%)$ \\
\hline
\end{tabular}

\section{Conclusion}

Online learning mode can effectively make up for space and time limit of face-toface education mode, but students need to own strong self-discipline ability to plan and arrange their learning. In a bid to deeply integrate advantages of online learning mode and face-to-face education mode, a blending learning mode was constructed on the basis of network learning space, and applied in teaching design practice of Digital Art. Based on proposing a MOOC video production method which can effectively reduce complicity and difficulty, the basic frame of network learning space was designed in this study. Then, the blending learning mode applicable to Digital Art teaching design was designed on the basis of network learning space. Teaching practice results indicate that, the blending learning mode based on network learning space can significantly improve teaching effect of Digital Art.

The effect is mainly embodied in the following aspects:

- Course production process in this study does not need professional picture and voice recording equipment, which brings convenience for teachers and contributes to teachers' teaching.

- The expression form of the course based on network learning space synthesizes MOOC technology, network learning space and blending learning forms. Teachers no longer need to ceaselessly switch over teaching display mode. The blending learning mode helps teachers focus on course content display, which more contributes to enhancing student-teacher interaction.

- Course content recording consistency of network learning space is high. Teaching activity design module can motivate students' learning interest so that students can be devoted to classroom interaction with independent study attitude.

- It is still necessary to improve practice process. Firstly, teachers' teaching concept and teaching status need to change. In blending learning mode based on network space, teachers need to change from dominant role in traditional education to learning resource maker organizer. Secondly, in blending learning mode, teachers need to make more efforts to guide and cultivate students' learning habits so that students can develop the habit of self-discipline and continuously learn with rich learning resources in network learning space. 


\section{$7 \quad$ Acknowledgement}

This work was supported by Research Fund for young teachers of University of Science and Technology Liaoning (601009822-19).

\section{References}

[1] Gibson, B.A., Puniwai, N. Developing an Archetype for Integrating Native Hawaiian Traditional Knowledge with Earth System Science Education. Journal of Geoscience Education, 2006, vol. 54(3), pp. 287-294. https://doi.org/10.5408/1089-9995-54.3.287

[2] Gandhi, K.I. A Teaching-Learning Model for Software Engineering Courses through Sensor-Based Cognitive Approach. International Journal of Engineering Education, 2016, vol. 32(2), pp. 915-926.

[3] Ji, H., Park, K., Jo, J., et al. Mining students activities from a computer supported collaborative learning system based on peer to peer network. Peer-to-Peer Networking and Applications, 2016, vol. 9(3), pp. 1-12. https://doi.org/10.1007/s12083-015-0397-0

[4] Chakraborty, B., Sinha, M. Student evaluation model using bayesian network in an intelligent E-learning system. Iioab Journal, 2016, vol. 7(2), pp. 51-60.

[5] Rovai, A.P. Sense of community, perceived cognitive learning, and persistence in asynchronous learning networks. Internet \& Higher Education, 2002, vol. 5(4), pp. 319332. https://doi.org/10.1016/S1096-7516(02)00130-6

[6] Cukurova, M., Avramides, K., Spikol, D., et al. An analysis framework for collaborative problem solving in practice-based learning activities:a mixed-method approach. Proceedings of the Sixth International Conference on Learning Analytics \& Knowledge, 2016, pp. 84-88. https://doi.org/10.1145/2883851.2883900

[7] Boiangiu, C.A., Constantin, A., Deliu, D. et al. Balancing Competition and Collaboration in a Mixed Learning Method. International journal of information and education technology, 2016, vol. 10, pp. 51-57.

[8] Duo, Z.J., Zhao, W., Li, Y.B., et al. Blended Learning Design Based on Online Learning Space from the Perspective of Problem-solving Learning. e-Education Research, 2018, vol. 28(2), pp. 32-38.

[9] Yang, L., Zhao, D.S. The Research on Blended Learning Which Based on Moodle. Journal of Capital Normal University (Natural Sciences Edition), 2010, vol. 31(1), pp. 6-9.

[10] Oh, S., Shah, D. Learning Mixed Multinomial Logit Model from Ordinal Data. Advances in Neural Information Processing Systems, 2014, vol. 1, pp. 595-603.

[11] Loibl, K., Roll, I., Rummel, N. Towards a Theory of When and How Problem Solving Followed by Instruction Supports Learning. Educational Psychology Review, 2017, vol. 29(4), pp. 1-23. https://doi.org/10.1007/s10648-016-9379-x

[12] Gillet, D., Jong, T.D., Sotirou, S., et al. Personalised Learning Spaces and Federated Online Labs for STEM Education at School. Global Engineering Education Conference, 2013, pp. 769-773. https://doi.org/10.1109/EduCon.2013.6530194

\section{$9 \quad$ Author}

Jian Wang is an associate professor in the University of Science and Technology Liaoning, Anshan, China (13332110005@sina.cn).

Article submitted 17 September 2018. Resubmitted 8 November 2018. Final acceptance 14 November 2018. Final version published as submitted by the author. 